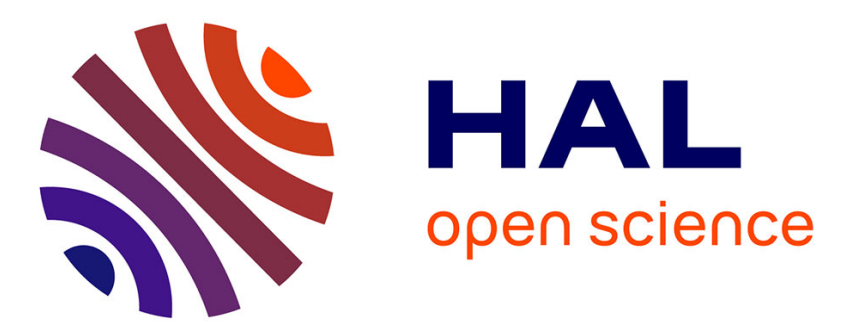

\title{
Impact of chronic oral mucosal disease on daily life: preliminary observations from a qualitative study
}

Richeal Ni Riordain, Sarah Meaney, Christine Mccreary

\section{To cite this version:}

Richeal Ni Riordain, Sarah Meaney, Christine Mccreary. Impact of chronic oral mucosal disease on daily life: preliminary observations from a qualitative study. Oral Diseases, 2010, 17 (3), pp.265. 10.1111/j.1601-0825.2010.01734.x . hal-00599894

\section{HAL Id: hal-00599894 https://hal.science/hal-00599894}

Submitted on 11 Jun 2011

HAL is a multi-disciplinary open access archive for the deposit and dissemination of scientific research documents, whether they are published or not. The documents may come from teaching and research institutions in France or abroad, or from public or private research centers.
L'archive ouverte pluridisciplinaire HAL, est destinée au dépôt et à la diffusion de documents scientifiques de niveau recherche, publiés ou non, émanant des établissements d'enseignement et de recherche français ou étrangers, des laboratoires publics ou privés. 


\section{ORALIDISEASES}

Impact of chronic oral mucosal disease on daily life: preliminary observations from a qualitative study

\begin{tabular}{|r|l|}
\hline Journal: & Oral Diseases \\
\hline Manuscript ID: & ODI-05-10-OM-1666.R1 \\
\hline Manuscript Type: & Original Manuscript \\
\hline Author: & $17-$ May-2010 \\
\hline Complete List of Authors: & $\begin{array}{l}\text { Ni Riordain, Richeal; Dental School and Hospital, Oral Medicine } \\
\text { Meaney, Sarah; University College Cork, Department of Public } \\
\text { Health and Epidemiology } \\
\text { McCreary, Christine; Dental School and Hospital, Oral Medicine }\end{array}$ \\
\hline Keywords: & $\begin{array}{l}\text { Qualitative study, Chronic oral mucosal conditions, Quality of life, } \\
\text { Oral Medicine }\end{array}$ \\
\hline &
\end{tabular}

\section{(5) scholaroNE" \\ Manuscript Central}




\section{Title:}

Impact of chronic oral mucosal disease on daily life: Preliminary

observations from a qualitative study

Running title:

A qualitative study of chronic oral mucosal conditions

\section{Keywords:}

Qualitative study, Chronic oral mucosal conditions, Quality of life, Oral

Medicine

Richeal Ni Riordain ${ }^{1 *}$, Sarah Meaney ${ }^{2}$, Christine McCreary ${ }^{1}$

${ }^{1}$ Oral Medicine Unit, Cork University Dental School and Hospital, Wilton, Cork, Ireland

${ }^{2}$ Department of Public Health and Epidemiology, Brookfield, Cork, Ireland ${ }^{*}$ Corresponding author.

Tel.: +35321 4901127; fax: +353214901179

E-mail addresses: richeal.niriordain@ucc.ie ; c.mccreary@ucc.ie 


\begin{abstract}
Objective: To explore the experience of daily life of persons with chronic oral mucosal conditions.

Methods: Purposive sampling was used to recruit patients from the Oral Medicine Unit of Cork University Dental School and Hospital. An experienced independent facilitator convened the focus groups and conducted individual interviews in a non clinical setting. Focus groups were mixed with regard to gender, age, chronic oral mucosal condition, time since diagnosis and severity. A total of 24 patients took part, including patients with oral lichen planus, mucous membrane pemphigoid, pemphigus vulgaris, recurrent aphthous stomatitis and orofacial granulomatosis.

Results: Analysis of the interviews revealed that patient views could be divided into the following themes - biopsychosocial issues, treatment limitations and side effects, unpredictability of the conditions and the potential for malignant transformation and issues for the healthcare professionals.

Conclusion: Chronic oral mucosal conditions impact upon the experience of daily life of patients in a variety of areas from physical health and functioning, to concerns about their future. The role of the oral medicine practitioner in treating patients with chronic oral mucosal diseases extends beyond active management and symptomatic relief to the management of all aspects of these conditions that impact upon their daily lives.
\end{abstract}




\section{Introduction}

Chronic oral mucosal conditions include autoimmune and inflammatory diseases of the soft tissue of the mouth. These conditions, like other diseases of the mouth, can result in considerable morbidity with physical, social and psychological consequences for patients (McGrath \& Bedi, 1999). They are commonly managed in an oral medicine clinical setting and are often long standing or recurrent, painful disorders. Some of these diseases can predispose to or lead to the development of life-threatening conditions (Hegarty et al., 2002a). Not only can these chronic oral mucosal conditions have an impact on the every day lives of patients but many of the treatment options available, and their side effects, can also influence their daily lives (Ni Riordain \& McCreary, 2010).

The importance of evaluating the patients' own perceptions of the impact of their health on daily living has been long established (Bowling, 1995). The Expert Patient was a document produced by the Department of Health in the UK in 2001 (DOH, 2001), which outlines the vital role of the patient in their own healthcare, and the insight available to healthcare professionals from patients with chronic conditions:

"An observation often made by doctors, nurses and other health professionals...is 'my patient understands their disease better than I do.'...today's patients with chronic diseases need not be mere recipients of care. They can become key decision-makers in the treatment process." This document further emphasises the value of the patients' contribution in providing key information regarding living with chronic conditions. 
Qualitative research methods, whereby patients are interviewed regarding their conditions, allow these diseases to be seen through the eyes of the patient. Streiner and Norman (2006) stated that clinicians could be considered expert at observation of the clinical manifestations of a disease but only those who have the condition can report on the more subjective dimensions of the condition. This type of data can therefore add to commonly recorded medical or epidemiological data and hence enhance patient care. The aims of this study were to use qualitative research methods to explore the experiences of patients with chronic oral mucosal conditions and to identify factors that influence patients' daily lives.

\section{Materials and Methods}

A purposive sample of participants with a chronic oral mucosal condition was recruited from the Oral Medicine Unit of Cork University Dental School and Hospital. The recruitment resulted in a sample of 24 participants with various chronic oral mucosal conditions including oral lichen planus, mucous membrane pemphigoid, pemphigus vulgaris, recurrent aphthous ulceration and orofacial granulomatosis. The purpose and methods of the study were explained to each participant in detail, both verbally and in written format. Participants were also made aware that their participation in the study was voluntary and each participant was interviewed with written informed consent. This study was approved by the Clinical Research Ethics Committee of the Cork Teaching Hospitals. 
Five focus groups were conducted with participants $(n=22)$. An experienced independent facilitator, who was unaware of the issues regarding oral mucosal disease, convened all focus groups and interviews in a non clinical setting. Purposive sampling was used and focus groups were mixed with regard to gender, age, chronic oral mucosal condition, time since diagnosis and severity (Table 1). Timetabling was flexible to facilitate diverse participation. Two participants were unwilling to attend the focus groups expressing anxiety regarding a group setting and requested individual interviews. These individual interviews were subsequently carried out. A topic guide, devised and piloted by the research group, was used but discussions were allowed to be flexible according to the experience of each participant. The focus groups and interviews were digitally recorded and field notes were also taken. The recordings were transcribed and participants were anonymised with each participant being assigned a participant number.

Transcripts were imported into NVivo software and a thematic analysis was undertaken. An interpretive methodology was utilised in order to identify key factors influencing participants' experiences of the various chronic oral mucosal conditions they were suffering from on a daily basis. The transcripts were analysed on a line by line basis independently by 2 researchers (RNR/SM). The transcripts were coded, this is a means of defining the data that is about to be analysed. Coding involves identifying passages of text that exemplify a descriptive idea and linking them together under a single idea or code. This process then allows the transcripts to be categorised and hence facilitates the identification of key themes. 


\section{Results}

Analysis of the data indicated four key themes in relation to patients' experiences of their chronic oral mucosal condition. These themes included:

1. biopsychosocial issues

2. treatment limitations and side effects

3. unpredictability of the conditions and the potential for malignant transformation

4. issues for the healthcare professionals

In the following paragraphs, direct quotations from patient interviews are used to illustrate these key themes.

\section{Theme 1: Biopsychosocial Issues}

There was clear evidence that chronic mucosal conditions had a major impact not only on physical functioning but also psychologically and socially. Each participant remarked on the difficulties which arose from the physical symptoms associated with their condition such as difficulties with the textures and temperatures of food irritating their mouths. However the majority of participants outlined how these difficulties lead to high levels stress and in some cases depression.

"You have to make a conscious effort to kind of distract yourself and not let it take over your life. It can make you very depressed. I've had it a long time now and l've gone through all different things and I had to kind of make a 
decision to say that this is not going to get me down because otherwise you mightn't get out of bed." Participant 1

This issue was reinforced when participants illustrated how limitations on diet or generally discomfort can lead to discomfort in social settings or a reluctance to partake in social outings.

"I would be at the restaurant and l'd be like, 'no sauce on that, and it doesn't come in a sauce does it?' And that would be absolutely no sauces, no soups, no additives and somebody once said, 'you know I heard someone asking for things like that and I thought that she was just being really difficult.' It can be actually something that affects you that badly." Participant 24

"I like doing loads of things. With this, when I go out now, you know when you're meeting people and you talk and you talk and you talk... just don't go out anymore because it is so sore when I am talking.'

Participant 2

The social element of this theme includes the attitudes and perceptions of family and friends regarding these conditions.

'they don't understand and like that...you know I could have a bad day at work but I am not inclined to say it is because of my mouth is really in agony" Participant 21 
“They kind of look at you and say 'What, what?' And ... it's as if you have leprosy."

Participant 22

\section{Theme 2: Treatment limitations and side effects}

Participants also indicated difficulties with the medications prescribed for the conditions. Some outlined how when initially diagnosed there was a period of trial and error whereby on occasion medications resulted in the symptoms of the condition been aggravated. A number of participants also raised concerns regarding the possible side effects of some medications used in the management of these conditions.

"The tears poured down my eyes, I was so bad with the mouthwash stinging me that I said to her 'I just can't do it!' You're after doing it thinking it would do you good and I think that it was after three days I rang her and I said 'I just can't' my tongue was red raw on fire." Participant 17

"I went to the chemist to get it [prescribed medication]... it was actually last Thursday week that I took the first one I think, you know after getting it and you know I was really afraid going into bed that night. I though 'Jesus I will never wake-up again' and I was glad to see daylight again on Friday morning!.” Participant 6

"The side effects are terrible from it... and I'm saying like, you know, is the cure going to be worse than the disease?" Participant 6 
"I would have concern about all medicines really because most if you look up there's some side effect with everything, the smallest little drug you're taking there's a side effect." Participant 13

Theme 3: Unpredictability of the conditions and the potential for malignant $\underline{\text { transformation }}$

Every participant highlighted the frustration with the unpredictable nature of the condition. They outlined one of the difficulties of living with the condition on a daily basis as being how irregular and erratic the occurrence of periods of flare with these diseases. Participants also expressed frustration at been unable to pinpoint the triggers that aggravate or exacerbate their condition.

"Because if there was a pattern you could actually follow, but there isn't you know. You could be good for a couple of months even and then all of a sudden they just get bad and then they continue bad for another couple of months and then and there's nothing that you can see that is happening regularly that you can see to cause it." Participant 4

"It can heal up temporarily and you think you got rid of it. And the next thing back it comes, fresh as paint." Participant 22

Due to the unpredictable nature of the disease participants stated that they would need to be prepared at all times for any unexpected flare-up. 
"I wouldn't go on holidays without taking a large dose of steroids with me. I'll always have them there." Participant 16

"It influences everything, yeah and if you make any plans to go for an evening or for a weekend away in Ireland or anything, you would be praying that it wouldn't flare up on your face... It dominates my life."Participant 24

A number of participants indicated that the malignant potential of oral lichen planus was one of their key concerns.

"You'll always keep an eye on it if it gets sort of serious then you're wondering is it developing into something else but..." Participant 10

"I suppose you know I was taken aback by that fact that $0.1 \%$ or something can turn cancerous and all that kind of thing. "Participant 12

"Well that would be my thing, the fear of cancer." Participant 18

“'The Big C' that's always a big concern for everybody" Participant 13

However participants clearly outlined their satisfaction with the frequency of regular review. One participant described this as been comforting.

Theme 4: Issues for the healthcare professionals

Participants expressed clear frustration with the delay in diagnosing their condition, with some reporting a delay of up to a year. 
"Well my dentist started treating me for thrush...then in the end I kind of said 'This isn't right. This is ridiculous.' In the end he said to me, 'Erah, you know everyone has something, you know.' Put up with it." Participant 2

"So I went to the dentist... and he was giving me lots of antibiotics. Then I went to the doctor and the doctor was treating it for ahhh fungal ummm conditions." Participant 7

"I feel I wasted nearly 12 months of my life before I got a definite diagnosis." Participant 18

"But its more manageable now but yeah I really, I resent the fact that it took so long to get anything, to get any information and to get any assistance with it really." Participant 20

However once diagnosed participants also indicated that other healthcare professionals would question recommended treatments or provide conflicting advice.

"The chemist didn't want to give it [prescribed steroid] to me. He said 'that will strip your lips'. And another chemist said the same thing to me, 'don't do anything with that' he said 'it will hurt your lips' and I knew my lips were been stripped so I won't take anything." Participant 2 
"My local chemist, she called me over to the corner and there was a big like discussion, you know. Did I know, did I realise what I was taking?"

Participant 6

\section{Discussion}

The use of qualitative methods in health services research has become more widespread over the last number of years. Qualitative data are gathered via in-depth interviews and focus groups allow issues to not only be explored in detail but also to allow clarification to be sought in a comfortable environment. Focus groups are types of group interviews that rely upon communication between the research participants in order to obtain data and are particularly useful in investigating people's experiences of procedures or conditions (Travess et al., 2004).

Patient reported outcome measures are being used to a limited extent in oral medicine (Ni Riordain \& McCreary, 2010) with the oral health related quality of life and general quality of life of patients with oral lichen planus (Tabolli et al., 2009), pemphigus (Paradisi et al., 2009) and recurrent aphthous stomatitis (Mumcu et al., 2007) having been reported in the current literature. These studies regarding quality of life and chronic oral mucosal diseases use questionnaire based outcome measures to quantify the impact of theses conditions on the lives of patients. This is the first study in which qualitative research methods were used to report patient own perceptions of the impact of chronic oral mucosal conditions. The use of focus groups and interviews 
facilitate the expression of information and experiences that may be excluded or under developed with the used of quality of life questionnaires. The study highlights a number of areas of concern for patients with chronic oral mucosal conditions that are of relevance to healthcare workers, and in particular oral medicine practitioners.

As to be expected with chronic oral mucosal conditions the pain and discomfort experienced by the patients were foremost when discussing experiences of their daily lives. With these symptoms of pain one could also expect interference with oral functioning such as alteration of the diet and limitation of the types of food and drinks consumed. Oral pain and limitation of function could also lead to difficulty in social settings resulting in embarrassment for patients.

The unpredictable nature of these chronic conditions leads to uncertainty about the future and frustration. Patients with oral lichen planus were particularly concerned with the malignant potential of the condition and patients with other diseases were worried about diseases progression and spread. Frustration with the chronicity of the conditions and the lack of a cure was widespread.

One of the themes uncovered in this qualitative process has implications not only for the treatment of an individual patient or of a condition but has wider significance for healthcare professionals. Diagnostic delay experienced by patients raises issues for practitioners at a primary care level. Patients 
reported significant delay in referring patients with both general medical and dental practitioners having prescribed multiple antibiotics and antifungals in the treatment of these conditions. An apparent lack of awareness of the clinical features of these chronic oral mucosal conditions is worrisome. A deficiency in the knowledge of primary care practitioners regarding the detection of oral malignancy has been well documented in the literature with educational models proposed for amelioration of this issue (Macpherson et al., 2003, Ni Riordain \& McCreary, 2009, Carter \& Ogden, 2007), however, this issue has not previously been highlighted with regard to chronic oral mucosal diseases.

Another possible cause for the delay in diagnosis is a lack of familiarity with the discipline of oral medicine and hence inappropriate referrals. Patients have frequently been seen previously by at least one other healthcare practitioner before being referred to an oral medicine clinic (Miller et al., 2001). In fact, Haberland et al (1999) found that patients have, on average, previously been seen by 2.2 health practitioners prior to an oral medicine visit. The promotion of knowledge of the oral cavity and of the diseases of the soft tissue could lead to more accurate and prompt referral. These timely and appropriate referrals could not only result in a reduction in the reported diagnostic delay for patients but also lead to the provision of a more time and resource efficient service. Unnecessary time spent at specialists' appointments can lead to increased waiting list times for those really in need of oral medicine services, increased cost both financially to the patient and from a time management perspective for 
the consultant and generally can result in inadequate patient care. The maximisation of hospital resources should be considered critical at a time when economic factors are leading to increased financial pressure in health care funding. The educational measures and the promotion of awareness of the speciality of oral medicine are therefore paramount to improve the management of chronic oral mucosal conditions.

Chronic oral mucosal conditions impact upon the experience of daily life of patients in a variety of areas from physical health and functioning, to concerns about their future. The role of the oral medicine practitioner in the treatment of patients with chronic oral mucosal diseases extends beyond active management and symptomatic relief to the management of all aspects of these conditions that impact upon their daily lives. Improvement of the knowledge base of general practitioner with regard to chronic oral mucosal diseases and the promotion of the specialty of oral medicine must also be addressed to help deal with the impact of these conditions on patients' lives. 


\section{References}

Bowling A (1995). Measuring Disease: A review of Disease Specific Quality of

Life Measurement Scales, Open University Press: Buckingham.

Carter LM and Ogden GR (2007). Oral cancer awareness of general medical and general dental practitioners. Br Dent J 203: E10; discussion 248-9.

DOH DoH (2001). The Expert Patient - A New Approach to Chronic Disease Management for the 21st Century In: DoH, ed. HMSO: London.

Haberland CM, Allen CM and Beck FM (1999). Referral patterns, lesion prevalence, and patient care parameters in a clinical oral pathology practice. Oral Surg Oral Med Oral Pathol Oral Radiol Endod 87: 583-8.

Hegarty AM, McGrath C, Hodgson TA and Porter SR (2002a). Patient-centred outcome measures in oral medicine: are they valid and reliable? Int $J$ Oral Maxillofac Surg 31: 670-4.

Hegarty AM, McGrath C, Hodgson TA and Porter SR (2002b). Patient-centred outcome measures in oral medicine: are they valid and reliable? International Journal of Oral and Maxillofacial Surgery 31: 670-674.

Macpherson LM, McCann MF, Gibson J, Binnie VI and Stephen KW (2003). The role of primary healthcare professionals in oral cancer prevention and detection. Br Dent J 195: 277-81; discussion 263.

McGrath C and Bedi R (1999). A review of the influences of oral health on the quality of life. Int J Health Prom \& Educ 37: 116-119.

Miller CS, Epstein JB, Hall EH and Sirois D (2001). Changing oral care needs in the United States: the continuing need for oral medicine. Oral Surg Oral Med Oral Pathol Oral Radiol Endod 91: 34-44. 
Mumcu G, Hayran O, Ozalp DO, Inanc N, Yavuz S, Ergun T and Direskeneli $H(2007)$. The assessment of oral health-related quality of life by factor analysis in patients with Behcet's disease and recurrent aphthous stomatitis. $J$ Oral Pathol Med 36: 147-52.

Ni Riordain R and McCreary C (2009). Oral cancer--current knowledge, practices and implications for training among an Irish general medical practitioner cohort. Oral Oncol 45: 958-62.

Ni Riordain R and McCreary C (2010). The use of quality of life measures in oral medicine: a review of the literature. Oral Diseases 9999.

Paradisi A, Sampogna F, Di Pietro C, Cianchini G, Didona B, Ferri R, Abeni D and Tabolli S (2009). Quality-of-life assessment in patients with pemphigus using a minimum set of evaluation tools. Journal of the American Academy of Dermatology 60: 261-269.

Streiner DL and Norman GR (2006). Health Measurement Scales A practical Guide to their Devleopemtn and Use, Oxford University Press: Oxofrd. Tabolli S, Bergamo F, Alessandroni L, Di Pietro C, Sampogna F and Abeni D (2009). Quality of Life and Psychological Problems of Patients with Oral Mucosal Disease in Dermatological Practice. Dermatology. Travess HC, Newton JT, Sandy JR and Williams AC (2004). The development of a patient-centered measure of the process and outcome of combined orthodontic and orthognathic treatment. J Orthod 31: 220-34; discussion 2012. 
Table1. Characteristics of participants

\begin{tabular}{|c|c|c|c|c|c|}
\hline Participant & Sex & Age & Condition & Severity ${ }^{i}$ & $\begin{array}{l}\text { Time since } \\
\text { diagnosis } \\
\text { (in months) }\end{array}$ \\
\hline 1 & $\mathrm{~F}$ & 75 & Oral Lichen Planus & Moderate & 69 \\
\hline 2 & $\mathrm{~F}$ & 48 & $\begin{array}{l}\text { Recurrent } \\
\text { Aphthous } \\
\text { Stomatitis }\end{array}$ & Severe & 72 \\
\hline 3 & $\mathrm{~F}$ & 66 & Oral Lichen Planus & Mild & 79 \\
\hline 4 & $\mathrm{~F}$ & 68 & $\begin{array}{l}\text { Mucous Membrane } \\
\text { Pemphigoid }\end{array}$ & Severe & 54 \\
\hline 5 & $\mathrm{~F}$ & 62 & Oral Lichen Planus & Moderate & 33 \\
\hline 6 & $M$ & 50 & Oral Lichen Planus & Mild & 49 \\
\hline 7 & $\mathrm{~F}$ & 71 & Oral Lichen Planus & Mild & 74 \\
\hline 8 & M & 64 & Oral Lichen Planus & Moderate & 12 \\
\hline 9 & $\mathrm{~F}$ & 72 & $\begin{array}{l}\text { Pemphigus } \\
\text { Vulgaris }\end{array}$ & Severe & 42 \\
\hline 10 & M & 69 & Oral Lichen Planus & Mild & 70 \\
\hline 11 & $\mathrm{~F}$ & 60 & Oral Lichen Planus & Severe & 75 \\
\hline 12 & M & 59 & Oral Lichen Planus & Moderate & 33 \\
\hline 13 & $M$ & 58 & $\begin{array}{l}\text { Mucous Membrane } \\
\text { Pemphigoid }\end{array}$ & Moderate & 26 \\
\hline 14 & $\mathrm{~F}$ & 44 & Oral Lichen Planus & Mild & 18 \\
\hline 15 & $\mathrm{~F}$ & 54 & Oral Lichen Planus & Moderate & 14 \\
\hline 16 & $\mathrm{~F}$ & 65 & Oral Lichen Planus & Moderate & 46 \\
\hline 17 & $\mathrm{~F}$ & 58 & Oral Lichen Planus & Mild & 74 \\
\hline 18 & $M$ & 68 & Oral Lichen Planus & Moderate & 36 \\
\hline 19 & $\mathrm{M}$ & 66 & $\begin{array}{l}\text { Pemphigus } \\
\text { Vulgaris }\end{array}$ & Severe & 18 \\
\hline 20 & M & 76 & Oral Lichen Planus & Moderate & 13 \\
\hline
\end{tabular}

Severity ${ }^{i}$ Time since

diagnosis

(in months) 
1

2

3

4

5

6

7

8

9

10

11

12

13

14

15

16

17

18

19

20

21
$21 \quad$ F $51 \quad$ Oral Lichen Planus $\quad$ Mild $\quad 8$

22 F $61 \quad$ Oral Lichen Planus Mild 13

$\begin{array}{lllll}23 & \mathrm{~F} & 37 & \text { Orofacial } & \text { Moderate } 8\end{array}$

Granulomatosis

$\begin{array}{lllll}24 & F & 33 & \text { Orofacial } & \text { Moderate }\end{array}$

Granulomatosis

i $\quad$ Mild $=$ Exacerbations managed well with topical agents

Moderate $=$ Systemic agents needed during periods of exacerbation

Severe $=$ Systemic agents needed longterm for management of the condition 